\title{
QUANTITATIVE STUDIES ON THE INTERACTION OF CONCANAVALIN A, THE CARBOHYDRATE- BINDING PROTEIN OF THE JACK BEAN, WITH MODEL CARBOHYDRATE-PROTEIN CONJUGATES*
}

\author{
R. N. IYER $†$ and I. J. GOLDSTEIN \\ The Deaprtment of Biological Chemistry, The University of Michigan School of Medicine, Ann Arbor, \\ Michigan 48 104, U.S.A.
}

(First received 24 June 1972; in revised form 30 October 1972)

\begin{abstract}
The interaction of concanavalin $A$ with a comprehensive series of carbohydrate-bovine serum albumin conjugates was investigated by agar gel diffusion and quantitative precipitation techniques. These studies showed that when conjugated to bovine serum albumin, those sugars which inhibited concanavalin A-polysaccharide interaction formed a precipitate with concanavalin $A$. The unexpected reactivity of the $p$-phenylazo $\beta$-D-glucopyranoside-bovine serum albumin conjugate is rationalized on the basis of inhibition data employing several aryl and alkylglycosides.
\end{abstract}

\section{INTRODUCTION}

Recent reports (Inbar and Sachs, 1969; Novogradsky and Katachalski, 1971; Powell and Leon, 1970; Weckster et al., 1968) on the mitogenic behavior and lymphocyte-transforming activity of concanavalin A have enhanced interest in concanavalin $A$, the phytohemagglutinin of the jack bean (Canavalia ensiformis) (Summer, 1919). We have been studying this protein for almost $10 \mathrm{yr}$ as a model for the antibody-antigen system and as a tool for probing the structure of carbohydrate-containing biopolymers.

Inasmuch as the primary event in many of the biological effects of concanavalin $A$ almost certainly involves the binding of this protein to glycoprotein or glycolipid constitutent of cell surfaces and membranes, we believe the following report should be of interest to those investigating these systems. We examine herein by means of the quantitative precipitin technique the interaction between concanavalin $A$ and synthetic glycoproteins. A qualitative report of these findings has already been published (Goldstein and Iyer, 1966).

\section{Materials and methods}

\section{EXPERIMENTAL}

L-Fucose, D-galactose, D-glucose, D-mannose, methyl $\alpha$ - and $\beta$-D-glucopyranoside, maltose and cellobiose octaacetate were purchased from Pfanstiehl Laboratories. Waukegan, Illinois. p-Nitrophenyl $\alpha$-D-glucopyranoside, p-nitrophenyl $\beta$-D-galactopyranoside and p-nitrophenyl 2-acetamido-2-deoxy- $\beta$-D-glucopyranoside were purchased from Koch-Light Laboratories, Colnbrook, Bucks,

\footnotetext{
*Supported by National Institutes of Health Research Grant AM-AI-10171.

+Present address: Department of Pediatrics Medical Center, Case-Western Reserve University Cleveland, Ohio 44106, U.S.A.
}

England. Gentiobiose and p-nitrophenyl $\beta$-lactoside were the generous gifts of Dr. P. Z. Allen, University of Rochester. Bovine serum albumin and defatted jack bean meal were products of General Biochemicals, Chagrin Falls, Ohio. Concanavalin A was prepared from jack bean meal by the method of Agrawal and Goldstein (1967).

Preparation of protein-carbohydrate conjugates. The protein-carbohydrate conjugates employed in this study were prepared by the diazotization of p-aminophenyl glycosides to the amino acyl side chains of bovine serum albumin (BSA). The procedure of Westphal and Feier (1956) was employed. Phenylazo-BSA was prepared by diazotization of aniline followed by coupling to BSA.

The p-nitrophenyl glycosides of the various sugars used in this study were purchased (see under Materials) or synthesized by established procedures and their melting points and specific optical rotations checked against literature values. $\mathrm{p}$-Nitrophenyl $\beta$-D-glucopyranoside and $\mathrm{p}$ nitrophenyl $\beta$-Dgalactopyranoside were prepared by the method of Goebel and Avery (1929); p-nitrophenyl $\alpha$-Dmannopyranoside was prepared by the prodecure of Conchie and Levvy (1962); p-nitrophenyl $\alpha$-L-fucopyranoside was synthesized according to Kabat (1961); p-nitrophenyl $\beta$-cellobioside, $\beta$-maltoside and $\beta$-gentiobioside were prepared by the procedures outlined by Babers and Goebel (1934); p-nitrophenyl $\beta$-sophoroside was made by the method of Iyer and Goldstein (1969). $p$-Nitrophenyl $\beta$-panoside was prepared by the action of $\beta$-glucosidase (Worthington Biochemical Corp.) on pnitrophenyl $\beta$-maltoside (Iyer, 1968).

Reduction of the p-nitrophenyl glycosides was carried out by catalytic hydrogenation at atmospheric pressure and temperature $\left(20-25^{\circ} \mathrm{C}\right)$ in methanol or aqueous methanol in the presence of Adam's catalyst. The theoretical consumption of hydrogen generally required $1-1-1 / 2$ hr.

Absorption spectra. The carbohydrate-BSA conjugates were dissolved in water, diluted to a concentration of $0.1 \mathrm{mg} / \mathrm{ml}$ and the spectra scanned in a Cary model 14 spectrophotometer from $500 \mathrm{~nm}$ to $240 \mathrm{~nm}$ using water as a blank. The manner in which the absorbance at $370 \mathrm{~nm}$ 
varied with the concentration of carbohydrate-BSA conjugate was recorded in a Beckman DU-2 spectrophotometer. The conjugate concentration was varied from 10 to $40 \mu \mathrm{g}$ nitrogen $/ \mathrm{ml}$.

Analysis of carbohydrate content of carbohydrateprotein conjugates. The carbohydrate content of the conjugates was determined by the anthrone method (Scott and Melvin, 1953). Best results were obtained if both the anthrone and the sugar solutions were precooled to $4^{\circ} \mathrm{C}$ before mixing. The heat of mixing was sufficient for color development.

The glucosamine content of the p-azophenyl-2-acetamido-2-deoxy- $\beta$-D-glucosida-BSA conjugate was determined by the Boas (1953) modification of the original Elson-Morgan procedure (1933) except that the Dowex column chromatography step was omitted since no interfering chromogen was present.

Nitrogen content of carbohydrate-BSA conjugates. The nitrogen content of the conjugates for the estimation of dry weights as well as for the determination of total nitrogen in the specific precipitates was determined by the ninhydrin method.

Gel diffusion studies. The procedure of Goldstein and So (1965) was employed for studying carbohydrateBSA-concanavalin A interaction. A solution of concanavalin $A(10 \mathrm{mg} / \mathrm{ml})$ was placed in the central well of the agar plate; peripheral wells contained the various conjugates. The plates were incubated at $25^{\circ} \mathrm{C}$ for $24 \mathrm{hr}$ after which they were rinsed with saline. Methyl $\alpha$-Dmannopyranoside solution $(10 \mathrm{mg} / \mathrm{ml})$ was layered over the plates and the time required for the disappearance of the bands was noted.

Quantitative precipitation analysis. Quantitative preciptin studies were performed in quadruplicate according to the procedure of So and Goldstein (1967). To specially constructed $3 \mathrm{ml}$ cenetrifuge tubes (Bello Glass, Inc., Vineland, New Jersey) was added increasing amounts of carbohydrate-protein conjugate $(2 \mu \mathrm{g}-1300 \mu \mathrm{g}$ nitrogen), the volume being adjusted to $0.5 \mathrm{ml}$ with water. To each tube was then added $2.1 M \mathrm{NaCl}(0.22 \mathrm{ml})$ and $0.1 \mathrm{M}$ phosphate buffer, pH $7.2(0.18 \mathrm{ml})$. The tubes were mixed on a vortex mixer and a constant amount of concanavalin A (39 $\pm 1 \mu \mathrm{g}$ nitrogen in $0.1 \mathrm{ml}$ of $1 M \mathrm{NaCl}$ solution) was added. The tubes were agitated on a vortex mixer, care being taken to prevent excessive foaming. Two sets of blanks were used, one containing all components except concanavalin A. These blanks were introduced in order to correct for non-specific aggregation of proteins. The tubes were allowed to stand at room temperature for 2 days with occasional agitation. The published procedure was then followed for nitrogen determination (So and Goldstein, 1967).

Determination of conjugate nitrogen in the precipitates. Each of the conjugates was dissolved in water and diluted to three different concentrations. The nitrogen content of the conjugates was determined by the ninhydrin method. The absorbance at $370 \mathrm{~nm}$ of the same solutions (determined in a DU-2 Beckman spectrophotometer) was plotted against conjugate concentration ( $\mu \mathrm{g}$ of nitrogen/ ml).

Washed concanavalin A-conjugate precipitates were dissolved in a solution ( $1 \mathrm{ml}$ ) of methyl $\alpha$-D-mannopyranoside $(10 \mathrm{mg} / \mathrm{ml})$ and the absorbance at $370 \mathrm{~nm}$ was measured. Methyl $\alpha$-D-mannopyranoside was shown to have no effect on the absorbance of the conjugates and concanavalin A has negligible absorption at $370 \mathrm{~nm}$. The conjugate nitrogen was then computed from the graph of absorbance at $370 \mathrm{~nm}$ vs $\mu \mathrm{g}$ of the appropriate conjugate nitrogen $/ \mathrm{ml}$.

Determination of concanavalin $A$ nitrogen in precipitates. The contribution of concanavalin $A$ to the total nitrogen in the precipitate was obtained by the difference in total nitrogen, determined by the ninhydrin method, and the conjugate nitrogen calculated from absorbance at $370 \mathrm{~nm}$ as described above.

\section{RESULTS}

Absorption spectra of BSA-carbohydrate conjugates. All of the carbohydrate-BSA conjugates prepared in the present investigation exhibited a broad peak between 340 and $420 \mathrm{~nm}$ with a $\lambda_{\max }$ at $370 \mathrm{~nm}$. Typical of these is the spectrum of the $p$-azophenyl $\alpha$-D-mannopyranoside-BSA conjugate depicted in Fig. 1. An absorption peak was not observed in the neighborgood of $480-490 \mathrm{~m} \mu$ which Higgins and Fraser (1952) showed to be characteristic of the bis coupled amino acids, suggesting that no bis coupling had occurred in this system.

Gelewitz et al. (1954) studied the spectra of arsonic acid-BSA conjugates and noted that the absorption maxima were dependent upon the number of diazobenzenearsonic acid introduced; with the introduction of only a few diazobenzenearsonic acid groups the absorption maxima was found to be at $332 \mathrm{~m} \mu$ shifting to $350 \mathrm{~m} \mu$ for extensively substituted proteins. The first peak corresponds closely to that found by Higgins and Frazer (1952) for tyrosine monoazobenzenesulfonic acid $(325 \mathrm{~nm})$; the second is in the region of that of histidine monoazobenzenesulfonic acid $(380 \mathrm{~m} \mu)$. On the basis of these observations the authors (Gelewitz et al., 1954) suggested that the azobenzene arsonic acid groups reacted first with the tyrosyl and then the histidyl residues. A similar shift in the absorption maximum was not observed with $p$-azophenyl $\beta$-maltoside-BSA con-

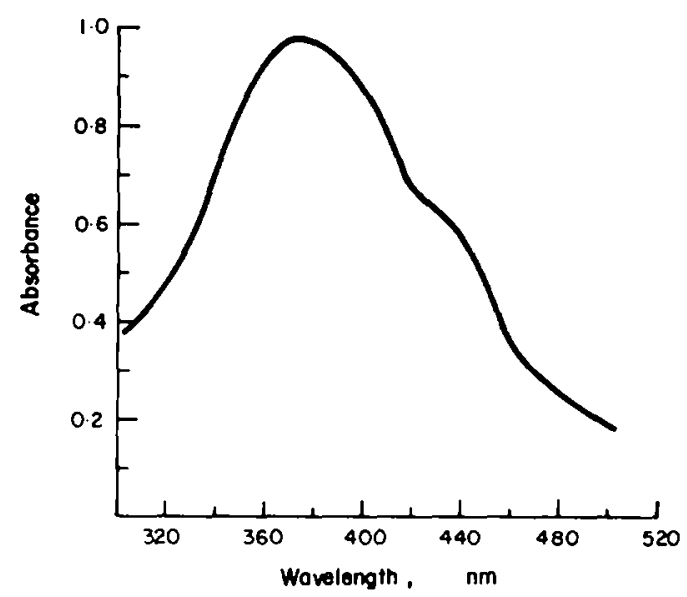

Fig. 1. Absorption spectrum of p-azophenyl $\alpha$-D-mannopyranoside-BSA conjugate $(350 \mu \mathrm{g} / \mathrm{ml}$ water $)$. 
jugates containing varying proportions of maltoside residues.

Solutions of all of the azoproteins followed Beer's Law at $370 \mathrm{~nm}$ in the concentration range studied (10-40 $\mu \mathrm{g}$ nitrogen $/ \mathrm{ml}$ ).

Carbohydrate content of carbohydrate-protein conjugates. The number of sugar residues per mole of BSA was calculated by assuming a mol. wt of 70,000 for BSA. The results are shown in Table 1 along with the absorbance at $370 \mathrm{~nm}$ of $100 \mu \mathrm{g}$ conjugate computed on a dry weight basis as determined by the ninhydrin method. A linear relationship was obtained when the number of sugar residues present in each conjugate was plotted against the absorbance at $370 \mathrm{~nm}$ of $100 \mu \mathrm{g}$ of conjugate (Fig. 2). This would suggest that the

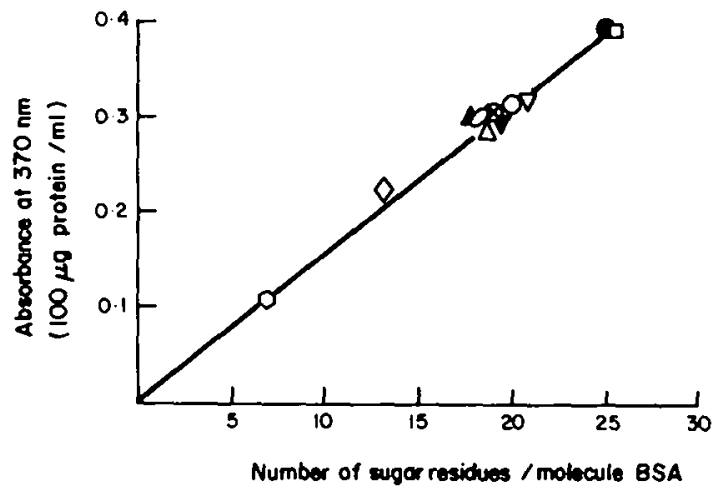

Fig. 2. Absorbance at $370 \mathrm{~nm}$ of carbohydrate-BSA conjugates $(100 \mu \mathrm{g})$ vs the number of sugar residues present per mole of BSA, 0 , maltoside (7); 0 , maltoside (14); $\Delta$, galactoside; $\Delta$, mannoside; $O$, gentiobioside; $O$, $\alpha$-glucoside; $\times$, lactoside; $\nabla$, cellobioside; $\nabla, \beta$-glucoside; , maltoside; $\square$, sophoroside. nature of the sugar residue has no effect on the absorbance at $370 \mathrm{~nm}$.

Agar gel diffusion studies. Demonstration of the ability of concanavalin $A$ to form a precipitin band with various carbohydrate-BSA conjugate is presented in Fig. 3. The p-azophenyl conjugates containing glucose (wells 1 and 3) and maltose (well 5) reacted with concanavalin A whereas those BSA conjugates of cellobiose (well 2) and galactose (well 8) did not. In other studies, BSA conjugates containing D-mannose, 2-acetamido-2-deoxy-Dglucose and sophorose also produced precipitin bands.

The time required for the dissolution of the various conjugate-concanavalin A precipitin bands with methyl $\alpha$-D-mannopyranoside $(10 \mathrm{mg} / \mathrm{ml})$ may be taken as a measure of the relative binding strengths of the conjugate-concanavalin A complexes. The time required for the dissolution of the D-mannose conjugate was $300 \mathrm{~min}$ compared to that of $\mathbf{4 0}$ min required for the maltose conjugate ( 25 residues maltose/BSA molecule). The precipitin band formed by the interaction of concanavalin $A$ with the $p$-azophenyl-2-acetamido-2-deoxy- $\beta$-Dglucopyranoside-BSA conjugate disappeared in 15 min suggesting it to be the weakest of the interacting carbohydrate-BSA conjugates.

Quantitative precipitation studies. Quantitative precipitation curves were conducted on all of the carbohydrate-protein conjugates described in this study. A typical study is shown in Fig. 4 in which the $p$-azophenyl $\alpha$-D-mannopyranoside-BSA conjugate is the precipitating species. This conjugate, in agreement with all our previous inhibition studies (Goldstein et al., 1965b; Poretz and Goldstein, 1970; So and Goldstein, 1967b, 1968b; Smith and Goldstein, 1967) and precipitation studies

Table 1. Relationship between the number of sugar residues per mole of BSA and absorbance at $370 \mathrm{~nm}$

\begin{tabular}{|c|c|c|}
\hline $\begin{array}{c}\text { Nature of } \\
\text { sugar residue }\end{array}$ & $\begin{array}{c}\text { Number of sugar } \\
\text { residues per mole } \\
\text { BSA }\end{array}$ & $\begin{array}{l}\text { Absorbance at } 370 \mathrm{~nm} \\
\text { for } 100 \mu \mathrm{g} \text { protein } / \mathrm{ml}^{\text {a }}\end{array}$ \\
\hline \multicolumn{3}{|l|}{ p-azophenyl 2-acetamido-2-deoxy- } \\
\hline$p$-azophenyl $\beta$-cellobioside & $\begin{array}{l}16 \cdot 0 \\
18.9\end{array}$ & $\begin{array}{l}0.338 \\
0.307\end{array}$ \\
\hline$p$-azophenyl $\alpha$-L-fucopyranoside & $21 \cdot 7$ & 0.335 \\
\hline$p$-azophenyl $\beta$-D-galactopyranoside & $18 \cdot 0$ & $0 \cdot 280$ \\
\hline$p$-azophenyl $\alpha$-D-glucopyranoside & $19 \cdot 8$ & 0.314 \\
\hline$p$-azophenyl $\beta$-D-glucopyranoside & $20 \cdot 5$ & 0.332 \\
\hline$p$-azophenyl $\beta$-gentiobioside & $17 \cdot 7$ & 0.293 \\
\hline$p$-azophenyl $\beta$-lactoside & $19 \cdot 0$ & 0.304 \\
\hline$p$-azophenyl $\beta$-maltoside & 6.9 & $0 \cdot 108$ \\
\hline$p$-azophenyl $\beta$-maltoside & 13.6 & 0.225 \\
\hline$p$-azophenyl $\beta$-maltoside & $25 \cdot 0$ & 0.393 \\
\hline$p$-azophenyl $\alpha$-D-mannopyranoside & $18 \cdot 5$ & 0.285 \\
\hline$p$-azophenyl $\beta$-panoside & $18 \cdot 2$ & 0.282 \\
\hline$p$-azophenyl $\beta$-sorphoroside & $25 \cdot 0$ & 0.392 \\
\hline
\end{tabular}

Dry weight basis. 


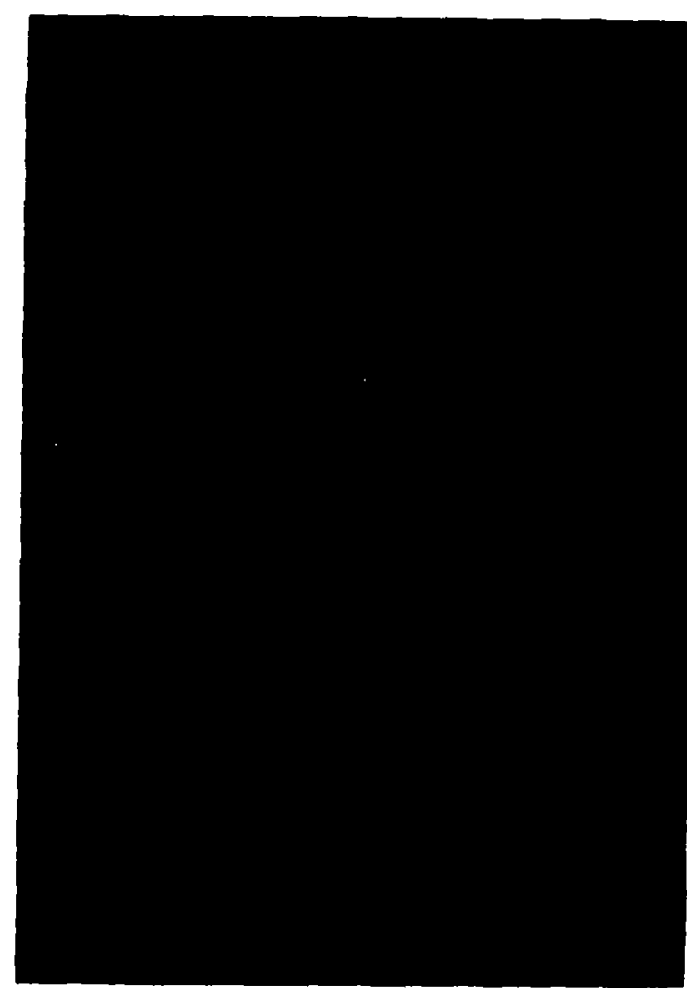

Fig. 3. Agar gel diffusion patterns of concanavalin A with representative carbohydrate-BSA conjugates. Central well contains concanavalin $A(0.1 \mathrm{ml}, 10 \mathrm{mg} /$ ml). Peripheral wells: 1 . p-azophenyl $\beta$-maltoside; 2 . $p$-azophenyl $\beta$-cellobioside; 3. $\rho$-azophenyl $\beta$-D-glucopyranoside; 4 . Saline control; 5. $p$-azophenyl $\alpha$-D-glucopyranoside; 6. p-azophenyl $\beta$-galactoside. Conjugate concentration: $1 \mathrm{mg} / \mathrm{ml}$.

(Goldstein and So, 1965; Goldstein et al., 1965a, 1969; Robinson and Goldstein, 1970; So and Goldstein, 1968b), is by far the most reactive of the carbohydrate-protein conjugates. The entire quantity of concanavalin A (39 $\mu \mathrm{g}$ nitrogen) was precipitated by $26 \mu \mathrm{g}$ conjugate nitrogen. The contribution of both conjugate and concanavalin $\mathbf{A}$ nitrogen is also shown in Fig. 4.

The maltose conjugate ( 25 residues of maltose per mole BSA) was next in order of reactivity, precipitating 90 per cent of the added concanavalin $A$ at a concentration of $125 \mu \mathrm{g}$ conjugate nitrogen (Fig. 5). The effect of the number of sugar residues per mole of $\mathrm{BSA}$ on precipitate formation is also shown. As can be seen from Fig. 5 the maltose conjugate containing 25 residues is the most reactive, followed in order of reactivity by the 13.6 and 6.9 residue conjugates.

Figure 6 represents the precipitation curve obtained when concanavalin $A$ interacts with the $p$-azophenyl $\beta$-panoside-BSA conjugate. Panose is a glucose trisaccharide $(O-\alpha$-D-glucopyranosyl-

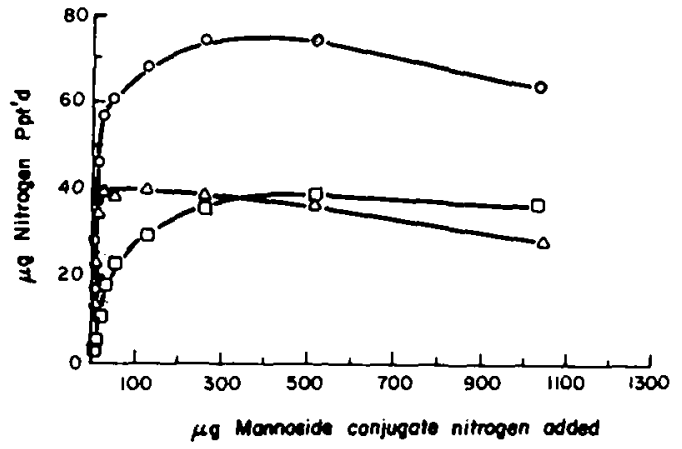

Fig. 4. Quantitative precipitin curve of p-azophenyl $\beta$-D-mannopyranoside-BSA conjugate with conavalin $A$. $O$, total nitrogen precipitated; $\triangle$, concanavalin $A$ nitrogen precipitated; $\square$, conjugate nitrogen precipitated. Concanavalin $A, 39 \mu \mathrm{g}$ nitrogen per tube.

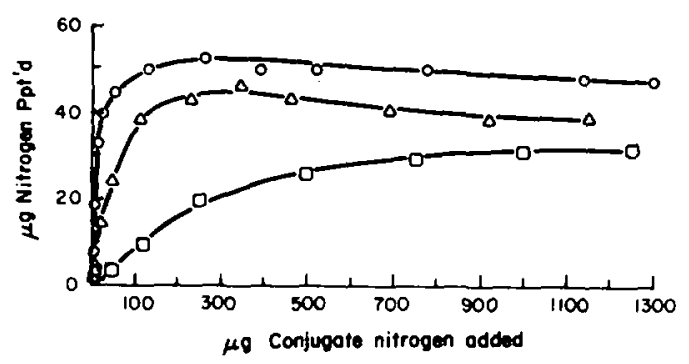

Fig. 5. Comparison of precipitating power of $p$-azophenyl $\beta$-maltoside-BSA conjugate containing varying amounts of maltoside residues. $O, 25$ maltoside residues/ mole BSA; $\triangle, 13.6$ maltoside residues/mole BSA; $\square$, 6.9 maltoside residues/mole BSA. Concanavalin A, 39 $\mu g$ nitrogen per tube.

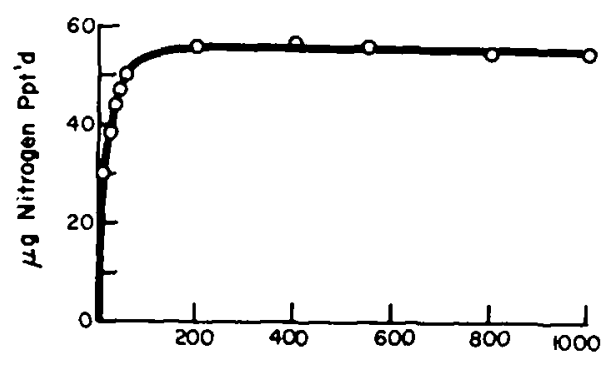

$\mu g$ Panoside conjugate nitrogen added

Fig. 6. Quantitative precipitin curve of $p$-azophenyl $\beta$ panoside-BSA conjugate with concanavalin A. Concanavalin A, 40.1 $\mu \mathrm{g}$ nitrogen per tube.

$(1 \rightarrow 6)-O-\alpha$-D-glucopyranosyl-( $1 \rightarrow 4)$-D-glucose) containing a terminal nonreducing $\alpha$-D-glucopyranosyl residue joined to the subterminal glucose by an $\alpha-(1 \rightarrow 6)$-glucosidic bond. The $\alpha-(1 \rightarrow 6)$ glucosidic linkage is the most reactive $\alpha$-D-glucosidic bond toward concanavalin A (Goldstein et al., 1965b; Smith and Goldstein, 1967; So and Goldstein, 1967b). 
The quantitative precipitation curve for the $p$ azophenyl $\beta$-sophoroside-BSA conjugate is shown in Fig. 7 along with the contribution of each reactant to the total nitrogen precipitated. It has been shown conclusively (Goldstein et al., 1967) that the concanavalin A combining sites interact with the C-3, C-4 and C-6 hydroxyl groups of the reducing D-glucopyranosyl residue of sophorose derivatives in distinction to combination with similar hydroxyl groups of the nonreducing D-glucopyranosyl residue of $\alpha$-linked glucose disaccharides.

As expected, several carbohydrate-BSA conjugates failed to react to any meaningful extent. Table 2 lists these unreactive conjugates along with the quantitative data establishing this point. In virtually every case, the carbohydrate-protein conjugates unreactive with concanavalin $A$ contain sugars which fail to inhibit the concanavalin Apolysaccharide interaction.

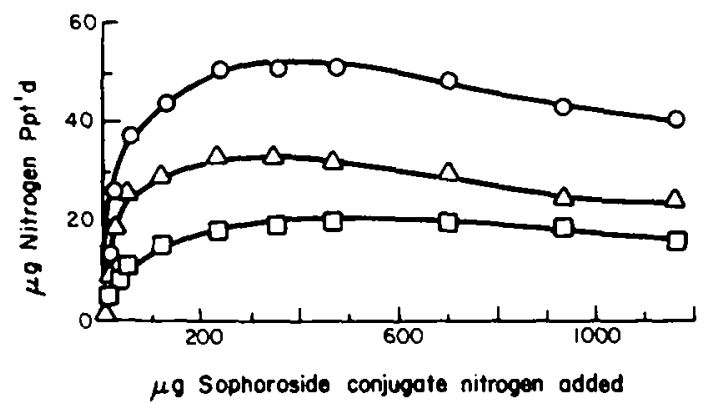

Fig. 7. Quantitative precipitin curve of $p$-azophenyl $\beta$ sophoroside-BSA conjugate with concanavalin A. $O$, total nitrogen precipitated; $\Delta$, concanavalin $A$ nitrogen precipitated: $\square$, conjugate nitrogen precipitated. Concanavalin $\mathrm{A}, 40 \mu \mathrm{g}$ nitrogen per tube.

Table 2. Interaction of concanavalin A with unreactive carbohydrate-protein conjugates ${ }^{\mathrm{a}}$

\begin{tabular}{lcc}
\hline $\begin{array}{c}\text { Nature of } \\
\text { sugar residue }\end{array}$ & $\begin{array}{c}\text { quantity of } \\
\text { conjugate } \\
\text { added } \\
\text { ( } \mu \text { g nitrogen) }\end{array}$ & $\begin{array}{c}\text { Amount of total } \\
\text { nitrogen precipitated } \\
(\mu g \text { nitrogen) }\end{array}$ \\
\hline$\beta$-D-galactoside & 51 & 0.5 \\
$\alpha$-L-fucoside & 204 & 0.8 \\
$\beta$-Cellobioside & 87 & 0.7 \\
$\beta$-Gentiobioside & 175 & 1.2 \\
$\beta$-Lactoside & 655 & 0.3 \\
BSA & 67 & 0.7 \\
Azophenyl-BSA & 670 & 0.4 \\
& 675 & 0.6 \\
& 150 & 0.7 \\
& 150 & 0.8 \\
\hline
\end{tabular}

aConcanavalin A; $39 \pm 1 \mu \mathrm{g}$ Nitrogen per tube.
Two interesting points concerning the amount of nitrogen precipitated by $600 \mu \mathrm{g}$ (nitrogen) of BSA and phenylazo-BSA require comment. First, it is known that most commercial samples of BSA, even though crystalline, contain small quantities of impurities, some of which may be glycoproteins. We believe that some of these serum glycoproteins contain the terminal nonreducing $\alpha$-D-glucopyranosyl (or its 2-acetamido-2-deoxy derivative) or most probably $\alpha$-D-mannopyranosyl residues which are requisite for interaction with concanavalin $A$. After synthesis of the carbohydrate-BSA conjugates, this complication appears to have disappeared. This is evident from an examination of the data on the D-galactoside, cellobioside, lactoside and gentiobioside conjugates which are essentially unreactive with concanavalin A (Table 2). The second point concerns the reactivity of the phenylazoprotein. It is known that the concanavalin $A$ molecule contains a region, adjacent to the carbohydrate-binding site, that interacts specifically with aromatic moieties (Goldstein and Iyer, 1966; Poretz and Goldstein, 1968, 1970, 1971). Thus it is possible that the phenylazo group of the phenylazo-BSA conjugate interacts with concanavalin $A$ at this aromatic binding site. However, when carbohydrate residues are glycosidically bound to the para position of the phenylazo-BSA conjugate (as is the case of all the carbohydrate-BSA conjugates described in this study) the phenylazo residues are no longer capable of interacting with the phenylbinding region on the concanavalin $A$ molecule.

Figure 8 compares the relative reactivity of the various carbohydrate-BSA conjugates examined in this study. It is interesting that the $p$-azophenyl $\beta$-D-glucopyranoside-BSA conjugate is more reactive than the anomeric $\alpha$-glucoside, despite the fact that both conjugates contain approximately 20 sugar residues per mole BSA. Note also that the BSA conjugate of $p$-azophenyl 2-acetamido-2deoxy- $\beta$ D-glucopyranoside is the least reactive of the conjugates (cf. Table 4).

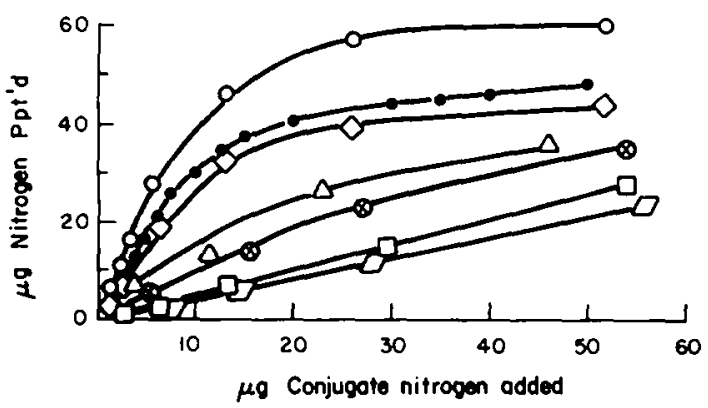

Fig. 8. Comparison of precipitating power of various carbohydrate-BSA conjugates, $O$, mannoside;, , panoside; $\vartheta$, maltoside ( 25 residues/mole BSA); $\triangle$, sophoroside; $O, \beta$-D-glucopyranoside, $\square, \alpha$-D-glucopyranoside; $\square, 2$-acetamido-2-deoxy- $\beta$-D-glucopyranoside. 
Solubility of the conjugate-concanavalin $A$ precipitates. The solubility (So and Goldstein, 1967a) of the concanavalin A-carbohydrate-BSA conjugates (Figs. 9 and 10) were determined by conducting the precipitations in $3 \mathrm{ml}$ centrifuge tubes with the total reaction ranging from $0.5 \mathrm{ml}$ to 2.0 $\mathrm{ml}$. The concanavalin A-mannoside-BSA conjugate precipitate (Fig. 9) had the lowest solubility with a value of $1.5 \mu \mathrm{g}$ nitrogen $/ \mathrm{ml}$. The maltoside conjugate containing 25 disaccharides residues had a solubility of $2.0 \mu \mathrm{g}$ nitrogen $/ \mathrm{ml}$. As the number of maltose residues were decreased, the solubility of the resulting precipitates with concanavalin A increased (Fig. 9).

Inhibition studies. Several aryl and alkyl glycosides were tested for their ability to inhibit the

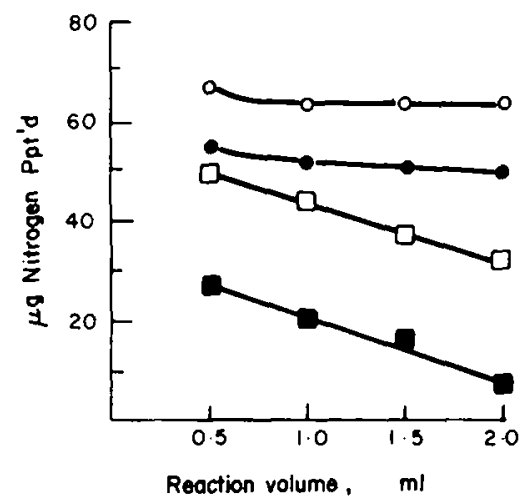

Fig. 9. Effect of reaction volume on concanavalin Aconjugate precipitation. $O$, mannopyranoside-BSA conjugate; maltoside-BSA conjugate ( 25 residues maltoside per mole BSA); $\square$, maltoside-BSA conjugate (13.6 residues maltoside per mole $B S A) ; \square$, maltoside-BSA conjugate ( 6.9 residues maltoside per mole $B S A)$.

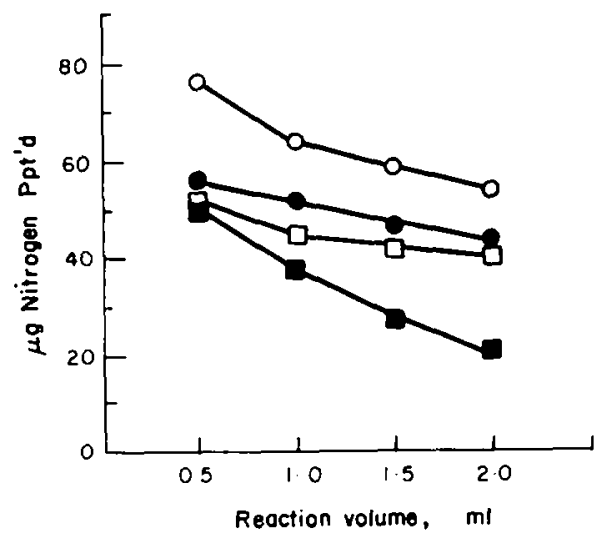

Fig. 10. Effect of reaction volume on concanavalin Aconjugates precipitation $O, \boldsymbol{\beta}$-D-glucopyranoside-BSA conjugate; $\alpha$-D-glucopyranoside-BSA conjugate; $\square$, sophoroside-BSA conjugate; $\square$, 2-acetamido-2-deoxy$\beta$-D-glucopyranoside-BSA conjugate. precipitation reaction between concanavalin $A$ and dextran. The amount of glycoside required for 50 per cent inhibition, obtained from a plot of percentage inhibition vs the logarithm of the $\mu$ moles of inhibitor added is presented in Table 3. As can be seen the amount of $\alpha$-glycoside required for 50 per cent inhibition is much less than for the corresponding $\beta$-glycoside. Methyl $\alpha$-D-glucopyranoside $(2.9 \mu$ mole for 50 per cent inhibition) is a better inhibitor than free glucose $(33 \mu$ mole for 50 per cent inhibition), which is a much better inhibitor than methyl $\beta$-D-glucopyranoside (100 $\mu$ mole for 50 per cent inhibition). Among the glycosides tested, $p$-aminophenyl $\alpha$-D-mannopyranoside is the most potent inhibitor, requiring only 0.15 $\mu$ mole for 50 per cent inhibition.

Aryl glycosides appear to be better inhibitors than alkyl glycosides. The effect of the phenyl ring on the inhibitory power can readily be seen by comparing the amount of glycosides required for 50 per cent inhibition: methyl $\beta$-D-glucopyranoside (100 $\mu \mathrm{mole})$ is a poor inhibitor compared to phenyl $\beta$-D-glucopyranoside $(26.5 \mu$ mole $)$ making the latter an even better inhibitor than free glucose (33 $\mu$ mole). A loss in the inhibitory power was observed when the aromatic ring in phenyl $\beta$-Dglucopyranoside was substituted by the cyclohexyl aglycone. Cyclohexyl $\beta$-D-glucopyranoside is a very poor inhibitor requiring $145 \mu$ mole for 50 per cent inhibition.

The nature of the substituents on the aromatic nucleus appears to have a pronounced effect on the inhibitory power of substituted phenyl $\alpha$-D-glycosides. Thus, the introduction of the electron withdrawing nitro group at the para position, as in $p$ nitrophenyl $\alpha$-D-glucopyranoside, converts the

Table 3. Inhibition of precipitation by various carbohydrates

\begin{tabular}{|c|c|}
\hline Saccharide & $\begin{array}{l}\mu \text { mole for } \\
50 \text { per cent } \\
\text { inhibition }\end{array}$ \\
\hline$p$-aminophenyl $\alpha$-D-mannopyranoside & 0.15 \\
\hline$p$-nitrophenyl $\alpha$-D-mannopyranoside & 0.52 \\
\hline$p$-aminophenyl $\alpha$-D-glucopyranoside & 0.73 \\
\hline Methyl $\alpha$-D-mannopyranoside & 0.90 \\
\hline Phenyl $\alpha$-D-glucopyranoside & $1 \cdot 50$ \\
\hline$p$-nitrophenyl $\alpha$-D-glucopyranoside & $2 \cdot 30$ \\
\hline Methyl $\alpha$-D-g]ucopyranoside & $2 \cdot 9$ \\
\hline Maltose & $6 \cdot 4$ \\
\hline$\alpha$-nitrophenyl $\beta$-D-glucopyranoside & $12 \cdot 2$ \\
\hline$\alpha$-aminophenyl $\beta$-D-glucopyranoside & $18 \cdot 5$ \\
\hline$p$-nitrophenyl $\beta$-D-glucopyranoside & $20 \cdot 5$ \\
\hline$p$-aminophenyl $\beta$-D-glucopyranoside & $20 \cdot 0$ \\
\hline Phenyl $\beta$-D-glucopyranoside & $26 \cdot 5$ \\
\hline D-glucose & $33 \cdot 0$ \\
\hline Methyl $\beta$-D-glucopyranoside & 100 \\
\hline Cyclohexyl $\beta$-D-glucopyranoside & 145 \\
\hline
\end{tabular}


Table 4. Relative reactivities of carbohydrate-BSA conjugates

\begin{tabular}{lc}
\hline \multicolumn{1}{c}{$\begin{array}{c}\text { Nature of sugar moiety } \\
(p \text {-azophenyl glycoside })\end{array}$} & $\begin{array}{c}\text { Amount of conjugate required } \\
\text { to precipitate } 20 \mu \mathrm{g} \\
\text { concanavalin A nitrogen } \\
(\mu \mathrm{g} \text { nitrogen })\end{array}$ \\
\hline$\alpha$-D-mannoside & $5 \cdot 0$ \\
$\beta$-panoside & $8 \cdot 5$ \\
$\beta$-maltoside (25 residues/BSA molecule) & $10 \cdot 5$ \\
$\beta$-sophoroside & $26 \cdot 0$ \\
$\beta$-D-glucoside & $43 \cdot 0$ \\
$\alpha$-D-glucoside & 105 \\
2-acetamido-2-deoxy- $\beta$-D-glucoside & 125 \\
\hline
\end{tabular}

glucoside into a poorer inhibitor $(2 \cdot 3 \mu$ mole for 50 per cent inhibition); conversely the introduction of an electron donating amino group at the para position as in $p$-aminophenyl $\alpha$-D-glucopyranoside enhances the potency of the inhibitor. Similar results were obtained with the substituted phenyl $\alpha$-D-mannopyranosides.

In the para substituted phenyl $\beta$-D-glucosides the observed differences in activity due to substituent effects were small. The reverse effect noted in the case of $o$ nitrophenyl and $o$-aminophenyl glucoside, i.e. $o$-nitrophenyl glucoside is a better inhibitor than $o$-aminophenyl glucoside, may be due to a steric effect.

In meta and para substituted benzene derivatives, the effect of structure on the rate of reaction and the equilibrium constant is described by Hammett's equation (Gould, 1959)

$$
\log K / K_{0}=\rho \sigma
$$

where $\sigma$ is a substituent constant (inductive and resonance or polar effects) which is independent of the nature of the reaction, $\rho$ is a proportionality constant dependent only on the reaction. $K$ and $K_{0}$ are the rate constants for the substituted and the unsubstituted compounds, respectively.

A linear relationship was obtained when the Hammett's substituent constants $(\sigma)$ were plotted against the ratio of the inhibitory constant ( $\mu$ mole required for 50 per cent inhibition) of the substituted to the unsubstituted phenyl $\alpha$-D-glucopyranoside (Fig. 11). Although more points are required to state categorically that a linear free energy relationship is operative in the concanavalin A-hapten system, there are definite indications that polar effects are involved in the case of substituted phenyl $\alpha$-D-gluco- and d-mannopyranosides.

\section{DISCUSSION}

Formation of a three dimensional lattice of sufficient molecular size is believed to be a prerequisite for the formation of a precipitate between antibody and antigen (Heidelberger, 1939; Marrack, 1938; Pauling, 1940). It is generally believed that a

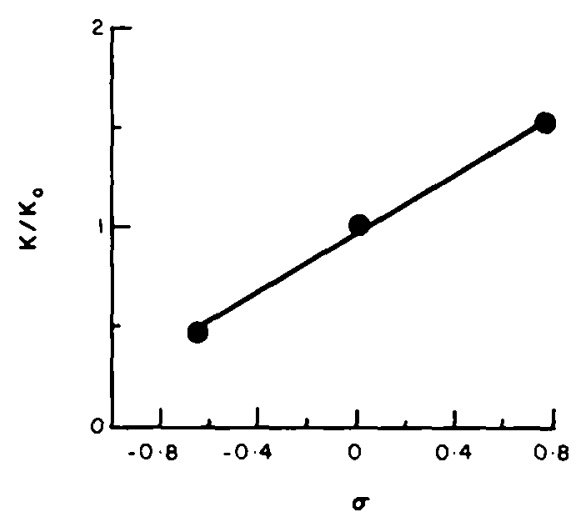

Fig. 11. Hammett plot of effect of substituents of substituted phenyl $\alpha$-glucosides on capacity of glycoside to inhibit concanavalin $\mathrm{A}$-destran interaction $\sigma$, substituent constant, $K$ and $K_{0}$ micromoles for 50 per cent inhibition for substituted and unsubstituted phenyl $\alpha$-D-glucopyranosides, respectively. (See Results for details).

specific precipitate is formed by combination of bivalent antibody (IgG) with polyvalent antigen molecule followed by the separation from solution of the insoluble antibody antigen complex. Pauling and his collaborators, using simple polvhaptenic substances as antigens, provided proof for the framework theory (Pauling et al., 1942a, b, c). This view was further supported by the electron micrographic studies of the ferritin-antiferritin system (Easty and Mercer, 1957).

A similar mechanism is visualized for precipitate formation between polysaccharide and concanavalin $\boldsymbol{A}$. In this system, polysaccharide containing multiple terminal non-reducing $\alpha$-D-glucosyl or $\alpha$ D-mannosyl residues is pictured as interacting with bivalent concanavalin A molecules (So and Goldstein, 1968; Yariv et al., 1968) to form a cross-linked complex. This concanavalin A-polysaccharide complex probably separates from solution as a consequence of its great molecular size.

If only the terminal nonreducing $\alpha$-D-glucopyranosyl and $\alpha$-D-mannopyranosyl units are the reactive sites in polysaccharide-concanavalin $\mathbf{A}$ 
interaction as suggested from earlier work from this laboratory, then a system containing a sufficient number of these reactive units should be capable of forming a precipitate with concanavalin A. Such a precipitating system was prepared by coupling, by means of diazotization, $p$-aminophenyl glycosides to BSA which serves as an inert macromolecular support.

The reaction of diazonium compounds with proteins has played an important role in immunochemistry since the discovery by Landsteiner and Lampl (1918) that small molecules coupled to protein through covalent linkage, elicit antibody specific to the introduced group. Goebel and Avery and their coworkers prepared protein-carbohydrate conjugates by the diazo coupling of $p$-aminophenyl glycosides to protein. They were able to show mono- and oligosaccharides are immunogenic when coupled protein and that the antibodies produced exhibited a specificity towards the introduced sugar. Since then a large number of carbohydrate-protein conjugates have been prepared (Allen et al., 1970; Arbkatsu et al., 1966; Gleich and Allen, 1965; Goldstein et al., 1967; Karush, 1957; Beiser et al., 1960).

All the carbohydrate-BSA conjugates which gave precipitin bands when tested against concanavalin $A$ in Ouchterlongy plates gave precipitinlike curves. The precipitin curves exhibited two distinct zones: concanavalin $A$ excess and an equivalence zone. However, the inhibition of the specific precipitates in the conjugate excess region was difficult to demonstrate. In this respect the precipitin curves resemble polysaccharide-antipolysaccharide system generally, in which it is relatively difficult to produce inhibition in the polysaccharide excess region, except in the case of relatively low mol. wt polysaccharides (Kabat and Berg, 1953). The concanavalin A carbohydrateprotein conjugate precipitin curves are very similar if not identical in shape to the concanavalin Aglycogen precipitin curves (So and Goldstein, 1969).

Among the conjugates which interacted with concanavalin $\mathrm{A}$, the mannose conjugate was most reactive. This is in general agreement with the findings of this laboratory that D-mannose-containing polysaccharides (e.g. $\alpha$-D-mannans from yeast) are most reactive with concanavalin $A$ and that $\alpha$-D-mannopyranosides are the most potent inhibitors of the concanavalin $A$ system. On the other hand, the BSA conjugate of $p$-azophenyl 2-acetamido-2-deoxy- $\beta$-D-glucopyranoside was the least reactive of the conjugates, a not unexpected result in view of the fact that $N$-acetyl-D-glucosamine is a rather poor inhibitor of the concanavalin $A$ system (Goldstein et al., 1965b; Smith and Goldstein, 1967).

Comparison of the data on the maltoside and cellobioside conjugates suggest that whatever the effect of the $p$-azophenyl group, precipitation with concanavalin $A$ is a function of the sugar moiety attached to the $p$-azophenyl group. The only difference between the cellobiose and maltose conjugates is the anomeric nature of the glucosidic bond linking the two D-glucopyranosyl residues. As expected the terminally $\alpha$-linked glucosyl residue of the maltose conjugate reacted with concanavalin $A$ whereas the $\beta$-linked terminal glucose of cellobiose did not react.

Assuming that the $p$-azophenyl group is common to all conjugates, the relative reactivity of the remaining conjugate can be determined. From the inhibition data (Goldstein et al., 1965b, 1967; Poretz and Goldstein, 1970; Smith and Goldstein, 1967) on dextran-concanavalin $A$ interaction, the following inhibitory order was obtained (Table 4):

mannose $>$ panose $>$ maltose $>$ sophorose $>$ Dglucose $>$ 2-acetamido-2-deoxy-D-glucose.

As expected the order of reactivity of the BSA conjugates of these sugars with concanavalin A was found to parallel the inhibition pattem (Fig. 8).

It was also shown that the number of sugars units conjugated to a molecule of BSA influence the precipitin reaction with concanavalin $A$. Thus the BSA conjugates containing $25,13.6$ and $7 p$-azophenyl $\beta$-maltoside residues per molecule of BSA precipitated 90 per cent, 62 per cent and 32 per cent, respectively, of the concanavalin $A$ added. This result may well be due to the decrease in the number of antigenic sites (maltoside residues) on the BSA molecule.

Incomplete precipitation of pure antibodies has been observed in some antibody-antigen systems. Singer et al. (1960), investigating the precipitating capacity of pancreatic ribonuclease with its antibodies observed that the precipitin curve was markedly dependent on the concentration of the antibody solution. At concentration of $0.32 \mathrm{mg} / \mathrm{ml} \mathrm{a}$ maximum of 45 per cent of the protein was precipitated. When the antibody concentration was increased 12 fold, 69 per cent of the antibody protein was precipitated. Incomplete precipitation was attributed to the relatively small number of antigenic sites on the ribonuclease molecule. It was also shown in the case of the ribonuclease-anti ribonuclease system, that a decrease in the number of antigenic sites appears to favor the formation of soluble aggregates (Pepe and Singer, 1959).

These data suggest furthermore, that branching per se such as occurs in glycogen and dextran is not a prerequisite for precipitate formation with concanavalin $A$, a requirement proposed by previous workers (Cifonelli et al., 1956 Manners and Wright, 1962). The necessary condition is rather the presence of multiple, terminal nonreducing $\alpha$-D-glucopyranosyl or $\alpha$-D-mannopyranosyl residues.

Previous communications have dealt with an aromatic binding site adjacent to the carbohydrate 
site in the concanavalin A molecule (Goldstein and Iyer, 1966; Poretz and Goldstein, 1968, 1970, 1971). We have reported that phenyl $\beta$-D-glucopyranoside binds to the active of concanavalin $A$ five times more avidly than methyl $\beta$-D-glucopyranoside. There was no correlation between the binding constants and the electronic properties of substituents of substituted phenyl $\beta$-D-glucopyranosides, although the nonpolar nature of orthoand meta- but not para-substituents is closely associated with the binding of aryl $\beta$-D-glucosides to concanavalin A (Poretz and Goldstein, 1971).

In contrast, phenyl $\alpha$-D-glucopyranoside is only approximately twice as good an inhibitor as methyl $\alpha$-D-glucopyranoside. Furthermore, the electronic effects of para substituents in phenyl $\alpha$-D-glucopyranoside are apparent, the $p$-aminophenyl $\alpha$ glucoside being 3.5 times more potent an inhibitor than $p$-nitrophenyl $\alpha$-glucoside and 10 times more potent than phenyl $\alpha$-glucoside. Indeed, these substituent effects may be related to their binding constants by the Hammett equation.

Still to be considered is the fact that although they contain the same number of glucoside residues, the $p$-azophenyl $\beta$-glucopyranoside-BSA conjugate is a better precipitant of concanavalin $A$ than the $p$-azophenyl $\alpha$-glucopyranoside-BSA conjugate (Fig. 8), this despite the fact that $p$-aminophenyl $\alpha-D$-glucopyranoside is a better inhibitor of the concanavalin $A$ system than the corresponding $\beta$ anomer $(0.73 \mu$ mole vs $20.0 \mu$ mole, respectively, for 50 per cent inhibition). Although we are unable at this time to provide an unequivocal answer to this intriguing discrepancy, it may be that the alpha p-azophenyl residue which is axially disposed in the $p$-azophenyl $\alpha$-D-glucopyranoside-BSA conjugate imposes a certain restriction in complementariness between the carbohydrate moiety of the BSA conjugate and the combining site of concanavalin A. On the other hand the beta p-azophenyl group, present in an equatorial position in the $p$-azophenyl $\beta$-D-glucopyranoside-BSA conjugate apparently offers less steric hindrance to the binding of the carbohydrate moiety by the protein.

\section{REFERENCES}

Agrawal B. B. L. and Goldstein I. J. (1967) Biochim. biophys. Acta 147, 262.

Allen P. Z., Goldstein I. J. and Iyer R. N. (1970) Immunochemistry 7, 567.

Arakatsu Y., Ashwell G. and Kabat E. A. (1966) $J$. Immun. $97,858$.

Avery O. T. and Goebel W. F. (1929) J. exp. Med. 50 , 533.

Babers F. H. and Goebel W. F. (1934) J. biol. Chem. 105, 473.

Beiser S., Burk G. C. and Tanenbaum S. W. (1960), J. molec. Biol. 2, 125 .

Boas N. B. (1953)J. biol. chem. 204, 553.

Cifonelli J. A., Montgomery R. and Smith F. (1956) J. Am. chem. Soc. 78, 2485.
Conchie J. and Levvy G. A. (1962) Meth. Carbohyd. Chem. 1, 313.

Easty G. C. and Mercer E. H. (1957) Discovery 18, 10.

Elson L. A. and Morgan W. T. J. (1933) Biochem. J. 27, 1824.

Gelewitz E., Riedman W. L. and Klotz I. M. (1954) Archs Biochem. Biophys. 53, 411 .

Gleich G. J. and Allen P. Z. (1965) Immunochemistry 2. 417.

Goebel W. F. and Avery O. T. (1929) J. exp. Med. 50, 521.

Goldstein I. J. and Iyer R. N. (1966) Biochim. biophys. Acta 121, 197.

Goldstein I. J. and So L. L. (1965) Archs Biochem. Biophys. 111, 407.

Goldstein I. J., Hollerman C. E. and Merrick J. M. (1965a) Biochim. biophys. Acta 97, 68 .

Goldstein I. J.. Hollerman C. E. and Smith E. E. (1965b) Biochemistry 4,876.

Goldstein I. J., Iyer R. N., Smith E. E. and So L. L. (1967) Biochemistry 6, 2373.

Goldstein I. J., So L. L., Yang Y. and Callies Q. C. (1969) J. Immun. 103, 695.

Gould E. S., (1959) Mechanism and Structure in Organic Chemistry, p. 220. Holt, New York.

Heidelberger M. (1939) Chem. Rev. 24, 323.

Hissins H. G. and Fraser D. (1952) Aust. J. Scientific Res. $5,736$.

Inbar M. and Sachs L., (1969) Nature, Lond. 223, 710.

Iyer R. N. (1968) Ph. D. Dissertation. State University of New York at Buffalo.

Iyer R. N. and Goldstein I. J. (1969) Carbohyd. Res. 11 , 241 .

Kabat E. A. and Berg D. (1953) J. Immun. 70, 514.

Kabat E. A. and Mayer M. M. (1961) Experimental Immunochemistry, 2nd Ed., p. 801. Thomas, Springfield, III.

Karush F. (1957) J. Am. chem. Soc. 79, 3380.

Landsteiner K. and Lampl H. J. (1918) Biochem. Z. 86, 343.

Manners D. J. and Wright A. (1962) J. Chem. Soc. 45, 92.

Harrack J. R. (1934, 1938) The Chemistry of Antigens and Antibodies, Report No. 230 of the Medical Research Council. H. M. Stat. Off., London.

Novogrodsky A. and Katchalski E. (1971) Biochim. biophys. Acta 228, 579.

Pauling L. (1940) J. Am. chem. Soc. 62, 2643.

Pauling L., Pressman D., Cambell D. H., and Ikeda C. (1942) J. Am. chem. Soc. 64, 3003.

Pauling L., Pressman D. and Cambell D. H., Ikeda C. and Ikawa M. (1942) J. Am. chem. Soc. 64, 2994.

Pauling L., Pressman D. and Ikeda C. (1942) J. Am. chem. Soc. 64, 3010.

Pepe F. A. and Singer S. J. (1959) J. Am. chem. Soc. 81, 3878.

Poretz R. D. and Goldstein I. J. (1968) Archs. Biochem. Biophys. 125, 1034.

Poretz R. D. and Goldstein I. J. (1970) Biochemistry 9, 2890.

Poretz R. D. and Goldstein I. J. (1971) Biochem. Pharm. 20, 2727.

Powell A. E. and Leon M. A. (1970) Exp. Cell. Res. 62 , 315.

Robinson R. and Goldstein I. J. (1970) Carbohyd. Res. $13,425$.

Scott T. A. and Melvin E. H. (1953) Analyt. Chem. 25. 1656. 
Singer S. J., Fothergilli J. E. and Sharnoff J. V. (1960) J. Am. chem. Soc. 82, 565 .

Smith E. E. and Goldstein I. J. (1967) Archs Biochem. Biophys. 121, 88.

So L. L. and Goldstein I. J. (1967a) J. biol. Chem. 242, 1617.

So L. L. and Goldstein I. J. (1967b) J. Immun. 99, 158.

So L. L. and Goldstein I. J. (1968a) Biochim. biophys. Acta $165,398$.
So L. L. and Goldstein I. J. (1968b) J. biol. Chem. 243, 2003.

So L. L. and Goldstein I. J. (1969), J. Immun. 102, 53.

Summer J. B. (1919) J. biol. Chem. 31, 137.

Weckster M., Levy A. and Jaffé W. G. (1968) Acta Cient. Venezolana 19, 154.

Westphal O. and Feier H. (1956) Chem. Ber. 89, 582.

Yariv J., Kalb A. J. and Levitzki A. (1968) Biochim. biophys. Acta. 165, 303. 